\title{
Al-Sb-Y (Aluminum-Antimony-Yttrium)
}

\section{Raghavan}

In the previous work on this ternary system, two isothermal sections have been reported: at $500{ }^{\circ} \mathrm{C}$ by [1971Mur] and at $527^{\circ} \mathrm{C}$ by [2003Zen]. The latter study was reviewed briefly by [2008Rag]. Recently, [2009Zha] reported a thermodynamic assessment of this system.

\section{Binary Systems}

The Al-Sb phase diagram depicts the stoichiometric compound AlSb (B3, Sphalerite-type cubic). The Al-Y phase diagram [Massalski2] has the following intermediate phases: $\alpha \mathrm{Al}_{3} \mathrm{Y}\left(D 0_{19}, \mathrm{Ni}_{3} \mathrm{Sn}\right.$-type hexagonal), $\beta \mathrm{Al}_{3} \mathrm{Y}\left(\mathrm{BaP}_{3}-\right.$ type rhombohedral), $\mathrm{Al}_{2} \mathrm{Y}$ (C15, $\mathrm{MgCu}_{2}$-type cubic), $\mathrm{AlY}$ ( $\mathrm{B}_{f}, \mathrm{CrB}$-type orthorhombic), $\mathrm{Al}_{2} \mathrm{Y}_{3}\left(\mathrm{Al}_{2} \mathrm{Zr}_{3}\right.$-type tetragonal), and $\mathrm{AlY}_{2}\left(C 23, \mathrm{Co}_{2}\right.$ Si-type orthorhombic). The Sb-Y phase diagram [Massalski2] depicts the following intermediate phases: $\mathrm{SbY}_{3}\left(\mathrm{PTi}_{3}\right.$-type tetragonal), $\mathrm{Sb}_{3} \mathrm{Y}_{5}\left(D 8_{8}\right.$, $\mathrm{Mn}_{5} \mathrm{Si}_{3}$-type hexagonal), $\mathrm{Sb}_{3} \mathrm{Y}_{4}\left(D 7_{3}, \mathrm{Th}_{3} \mathrm{P}_{4}\right.$-type cubic, stable between 2120 and $\left.1660{ }^{\circ} \mathrm{C}\right)$, and $\mathrm{SbY}(B 1, \mathrm{NaCl}$-type cubic).

\section{Computed Ternary Phase Equilibria}

[2009Zha] described the liquid, fcc, bcc, cph and rhombohedral phases as substitutional solutions. The binary compounds were treated as stoichiometric phases. The solubility of $\mathrm{Al}$ up to 27 at.\% in $\mathrm{Sb}_{3} \mathrm{Y}_{5}$ was taken into account. The binary descriptions were used from the literature data. The ternary interaction parameters were set to zero. The optimized parameters were listed. Two isothermal sections at 527 and $500{ }^{\circ} \mathrm{C}$ and a liquidus projection were computed by [2009Zha]. The computed isothermal section at $527{ }^{\circ} \mathrm{C}$ agrees with that determined experimentally by [2003Zen]. The computed isothermal section at $500{ }^{\circ} \mathrm{C}$ is shown in Fig. 1. The triangulations of $(\mathrm{Al})+\alpha \mathrm{Al}_{3} \mathrm{Y}+\mathrm{SbY},(\mathrm{Al})+\mathrm{AlSb}+\mathrm{SbY}$ and $\mathrm{AlSb}+\mathrm{SbY}$ $+(\mathrm{Sb})$ agree with those found by [1971Mur], who studied the system up to 33.3 at.\% Y. No experimental data are

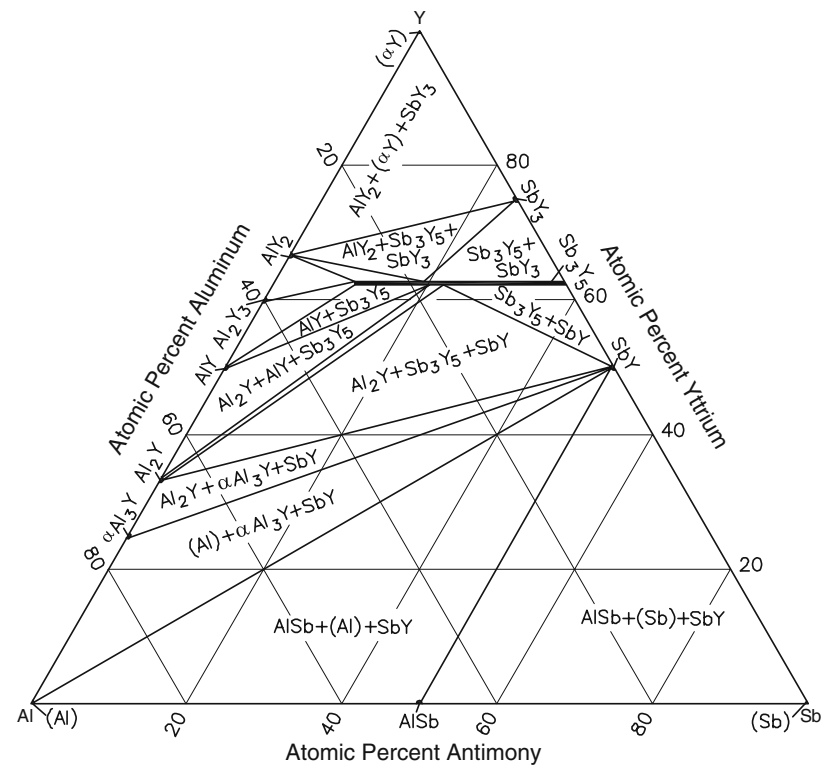

Fig. 1 Al-Sb-Y computed isothermal section at $500{ }^{\circ} \mathrm{C}$ [2009Zha]. Narrow two-phase regions are omitted

available for comparison with the computed liquidus projection of [2009Zha] (not shown here).

\section{References}

1971Mur: A.M. Muraveva, O.S. Zarechnyuk, and E.I. Gladyshevskii, The Systems Y-Al-Si $(\mathrm{Ge}, \mathrm{Sb})$ in the Range 0-0.33.3 at.\% Y, Neorg. Mater., 1971, 7(1), p 38-40, in Russian; TR: Inorg. Mater., 1971, 7(1), p 34-36

2003Zen: L. Zeng and S. Wang, The $800 \mathrm{~K}$ Isothermal Section of the Y-Al-Sb Phase Diagram, J. Alloys Compd., 2003, 351, p 176-179

2008Rag: V. Raghavan, Al-Sb-Y (Aluminum-AntimonyYttrium), J. Phase Equilib. Diffus., 2008, 29(2), p 190-191

2009Zha: L.G. Zhang, H.M. Chen, H.Q. Dong, G.X. Huang, L.B. Liu, and Z.P. Jin, Thermodynamic Description of the Al-Sb-Y System, J. Alloys Compd., 2009, 475, p 233-237 